\title{
How Does Beliefs Work as a Barrier Affecting Consumer's Attitude Towards Luxury Brand's Consumption
}

\author{
Huaiyue Yun ${ }^{1, *}$
}

\author{
${ }^{1}$ Shenzhen Vanke Meisha Academy, Shenzhen, China, 518000 \\ *Corresponding author. Email: 18211555321@163.com
}

\begin{abstract}
Consumer beliefs act as barrier towards purchasing luxurious and prominent brands among consumers. In recent decades, China has experienced significant growth in the consumption of luxury goods and services attributable to consumer beliefs. Our research focuses on consumer beliefs enhancing the consumption of valuable brands. Nevertheless, a literature gap exists on examining consumer beliefs acting as a barrier towards consumption of luxury brands inclusion of Louis Vuitton and Gucci. The research poses questionnaires that were administered on August 2021 to 30 random online consumers who were selected randomly through WeChat Application. We posit that the consumer's belief based on the integrity and benevolence of the luxurious product seller determines the dissatisfaction of consumers rather than satisfaction. Based on quantitative findings and literature analysis, the paper's main objective is to assess how consumer beliefs act as a barrier towards consumption of major luxurious brands based on perceived value, perceived risk, and perceived quality. Indeed, the consumer's beliefs strongly influence the purchasing behavior and patterns of global brands. We confirm that that: 1) The price of luxury goods and services limit the perceived value of the consumers. 2) Weakening brand value limits wealthy consumers and upper-class individuals from purchasing goods and services that everyone possesses. 3) There is an excellent shift from conspicuous consumption to inconspicuous consumption among the rich. 4) Religion beliefs and commitment limit the types of goods and services individuals can or may consume. 5) Consumer animosity limits the type of market, country, or group where individuals can purchase their goods and services. 6) The origin of a country where the good is produced or where the consumer lives limit the type of goods and services the consumer can buy. 7) Lastly, brand feedback also shapes the beliefs of the consumer towards product dissatisfaction. The findings contribute to existing literature.
\end{abstract}

Keywords: consumer, brand, consumption, upper-class, luxury goods

\section{INTRODUCTION}

\subsection{Background Information}

Consumer belief is an essential determinant of the wants and behaviors of consumers. Culture considerably impacts the patterns of decision-making and consumption patterns as it shapes the individual's belief system [1]. The logical and fundamental criterion that applies to each person acting in the capacity of a consumer is that the rational or estimated value of a product satisfies his primary motivation for an exchange. Delivering better value to consumers is a widely held belief among business leaders and academics. Historically, periods of democratized fake luxury and counterfeits for the middle classes encouraged higher social strata to innovate more. Currently, the separation of social class and luxury in a pseudonymous society, as well as the market for renting luxuries ranging from highly-priced automobiles to designer couture and designer bags on a short-term basis instead of purchasing them, have eroded the exclusivity of all but the most complex and costly luxury goods [2]. If a normal individual can pay a modest membership fee to use a BMW through a car sharing program for a specified amount of time, the BMW brand no longer represents a symbol of the driver's stature or financial capacity. 


\subsection{Statement of Problem}

Luxury consumption is no longer a social class indicator. Besides, luxury is now defined by significant goods and experiences that customers perceive as luxurious, instead of prominent premium brands. In an invisible society, strangers, parking valets, casual acquaintances, and hotel employees cannot distinguish between what is possessed and what is accessible for a little timeframe, or what is possessed at the expense of other consumption categories such as health care, literature, and education. Even cultural capital which consumers formerly had to earn through a privileged background and a superior education, may now be obtained with very few clicks in an era of the internet or artificial intelligence, at least in some consumption segments.

Therefore, the paper conducts a quantitative study to assess how beliefs act as barriers to consuming or purchasing luxurious brands. The paper seeks to provide an in-depth understanding of different consumption patterns. By incorporating quantitative results, this article contributes to the current knowledge and literature by conceptualizing luxury through the lens of the customer. This study contributes to the theoretical knowledge of which dimensions of belief systems significantly impact satisfaction and purchasing behavior. Additionally, this research offers guidelines to marketing consultants. It enables them to focus on the training and development programs of customer relationship employees on the different facets of trust that are most relevant to customer needs, such as prioritizing competence over altruism for occasional purchases or asserting benevolence for conceivably frequent purchases.

\subsection{Research Questions}

1. How do consumer beliefs negatively impact consumer behavior on luxury products?

2. What factors encompass consumer beliefs to avoiding significant brands?

\subsection{Research Significance}

The research offers practical marketing modes to sales and marketing representatives operating luxurious and high-end brands. The research findings will enable the sales and marketing department define certain elements of marketing that would enable them increase sales.

\section{METHODOLOGY}

\subsection{Research Methods and Objects}

Data for this research will be connected using questionnaires about the topic. The questionnaire method is a multi-step procedure. The researcher adopted questionnaires because they enhance the collection of both objective and subjective data in a larger sample size of the study population to get statistically significant results. The questions have been structured from a broad base to a simplified structure. Data will be collected from a WeChat group with about 30 participants. WeChat is one of the most popular social media platforms in China, and it will be a reliable source of data for this research. The data collected from the study participants will be analyzed using State 14. Stata is a data analysis tool that is mainly used by quantitative researchers.

\subsection{Research Results}

\subsubsection{Demographics}

The first section presents the demographics of data of the respondents. The study conducted an online study based on participants in WeChat social media platform. Based on the participants, $64 \%$ were female, and $36 \%$ were male. Based on income group, $23.33 \%$ of the respondents earn annual income of $\$ 1,000-\$ 5,000 ; 23.33 \%$ of the respondents earn annual income of $\$ 5,001$ $\$ 10,000 ; 33.33 \%$ of the respondents earn annual income of $\$ 10,001-\$ 15,000$, and $20 \%$ of the respondents earn annual income of $\$ 15,001-\$ 20,000$.

Table 1. Age

\begin{tabular}{|l|l|l|l|}
\hline SEX & FREQUENCY & PERCENT & CUM. \\
\hline MALE & 11 & 36.67 & 36.67 \\
\hline FEMALE & 19 & 63.33 & 100.00 \\
\hline TOTAL & 30 & 100.00 & \\
\hline
\end{tabular}

Table 2. Income

\begin{tabular}{|l|l|l|l|}
\hline $\begin{array}{l}\text { ANNUAL } \\
\text { INCOME }\end{array}$ & FREQ. & PERCENT & CUM. \\
\hline $\begin{array}{l}\mathbf{\$ 1 0 0 0 -} \\
\mathbf{\$ 5 , 0 0 0}\end{array}$ & 7 & $23.33 \%$ & 23.33 \\
\hline $\begin{array}{l}\mathbf{\$ 5 0 0 1 -} \\
\mathbf{\$ 1 0 , 0 0 0}\end{array}$ & 7 & $23.33 \%$ & 46.67 \\
\hline $\begin{array}{l}\mathbf{\$ 1 0 , 0 0 1 -} \\
\mathbf{\$ 1 5 , 0 0 0}\end{array}$ & 10 & $33.33 \%$ & 80.00 \\
\hline $\begin{array}{l}\mathbf{\$ 1 5 , 0 0 1 -} \\
\mathbf{\$ 2 0 , 0 0 0}\end{array}$ & 6 & $20.00 \%$ & 100.00 \\
\hline TOTAL & 30 & 100.00 & \\
\hline
\end{tabular}

Table 3. Ethnicity

\begin{tabular}{|l|l|l|l|}
\hline Ethnicity & Freq & Percent & Cum. \\
\hline $\begin{array}{l}\text { African- } \\
\text { American }\end{array}$ & 1 & 3.33 & 3.33 \\
\hline White & 8 & 26.67 & 30.00 \\
\hline $\begin{array}{l}\text { Native- } \\
\text { American }\end{array}$ & 5 & 16.67 & 46.67 \\
\hline Asia & 16 & 53.33 & 100.00 \\
\hline & 30 & 100.00 & \\
\hline
\end{tabular}




\subsubsection{Consumer Belief System}

\subsubsection{Price of Luxury Goods}

H1: Price of goods act as a barrier to consuming highvalue goods

$\mathrm{H} 2$ : Price of goods does not act as a barrier to consuming high-value goods

Based on the data from the respondents, most participants $(50 \%)$ consider price limits the consumption of luxurious goods.

Table 4. Price of Luxury Goods

\begin{tabular}{|l|l|l|l|}
\hline $\begin{array}{l}\text { DOES THE } \\
\text { PRICE OF } \\
\text { GOODS AFFECT } \\
\text { YOUR BELIEF } \\
\text { ON CONSUMING } \\
\text { LUXURIOUS } \\
\text { GOODS? }\end{array}$ & FREQ. & PERCENT & CUM \\
\hline $\begin{array}{l}\text { STRONGLY } \\
\text { DISAGREE }\end{array}$ & 4 & 13.33 & 13.33 \\
\hline DISAGREE & 1 & 3.33 & 16.67 \\
\hline NEUTRAL & 2 & 6.67 & 23.33 \\
\hline AGREE & 8 & 26.67 & 50.00 \\
\hline $\begin{array}{l}\text { STRONGLY } \\
\text { AGREE }\end{array}$ & 15 & 50.00 & 100.00 \\
\hline & 30 & 100 & \\
\hline
\end{tabular}

\subsubsection{Weakening Brand Value}

H1: A weakened brand value limits consumption of luxurious brands

H2: A weakened brand value does not limit the consumption of luxurious brands
Based on findings, most participants (46.67\%) strongly agree that a weakened brand value limits the consumption of luxurious brands.

Table 5. Weakening Brand Value

\begin{tabular}{|l|l|l|l|}
\hline $\begin{array}{l}\text { DO YOU } \\
\text { THINK } \\
\text { LUXURIOUS } \\
\text { BRANDS } \\
\text { ARE } \\
\text { FACING } \\
\text { WEAKENED } \\
\text { BRAND } \\
\text { VALUE? }\end{array}$ & FREQUENCY & PERCENT & CUM. \\
\hline $\begin{array}{l}\text { 5 } \\
\text { STRONGLY } \\
\text { DISAGREE }\end{array}$ & 3 & 3.33 & 3.33 \\
\hline DISAGREE & 2 & 10.00 & 13.33 \\
\hline NEUTRAL & 2 & 6.67 & 20.00 \\
\hline AGREE & 8 & 6.67 & 26.67 \\
\hline $\begin{array}{l}\text { STRONGLY } \\
\text { AGREE }\end{array}$ & 14 & 26.67 & 53.33 \\
\hline & 30 & 46.67 & 100.00 \\
\hline
\end{tabular}

\subsubsection{Inconspicuous consumption}

H1: Inconspicuous consumption limits the consumption of luxurious brands

$\mathrm{H} 2$ : Inconspicuous consumption does not limit consumption of luxurious brands

Based on findings, most participants (53\%) strongly agree that Inconspicuous consumption limits the consumption of luxurious brands.

Table 6. Conspicuous Consumption

\begin{tabular}{|l|l|l|l|}
\hline $\begin{array}{l}\text { DO YOU BELIEVE YOUR SHIFTING TO } \\
\text { CONSPICUOUS CONSUMPTION? }\end{array}$ & FREQ & PERCENT & CUM \\
\hline STRONGLY DISAGREE & 3 & 10.00 & 10.00 \\
\hline DISAGREE & 1 & 3.33 & 13.33 \\
\hline NEUTRAL & 3 & 10.00 & 22.33 \\
\hline AGREE & 7 & 23.33 & 46.67 \\
\hline STRONGLY AGREE & 16 & 53.33 & 100.00 \\
\hline & 30 & 100.00 & \\
\hline
\end{tabular}




\subsubsection{Religion}

H1: Religious beliefs limit the consumption of luxurious brands

H2: Religious beliefs do not limit the consumption of luxurious brands

Based on findings, most participants (50\%) strongly agree that religious beliefs limit the consumption of luxurious brands.

Table 7. Religious Beliefs

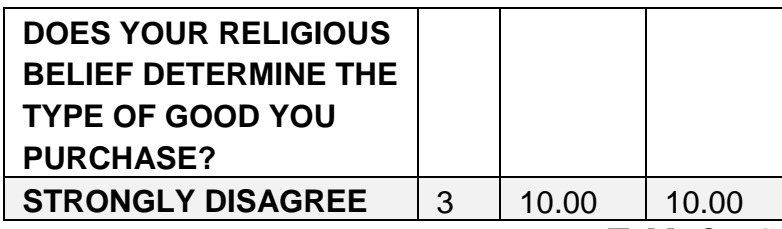

\begin{tabular}{|l|l|l|l|}
\hline DISAGREE & 2 & 6.67 & 16.67 \\
\hline NEUTRAL & 2 & 6.67 & 23.33 \\
\hline AGREE & 6 & 26.67 & 50.00 \\
\hline STRONGLY AGREE & 15 & 50.00 & 100.00 \\
\hline & 30 & 100.00 & \\
\hline
\end{tabular}

\subsubsection{Consumer Animosity}

H1: Consumer animosity limits the purchase of luxurious brands

H2: Consumer animosity does not limit the purchase of luxurious brands

Based on findings, most participants (46\%) strongly agree that consumer animosity limits luxurious brands' consumption.

\begin{tabular}{|l|l|l|l|}
\hline $\begin{array}{l}\text { DO YOU NEGLECT CERTAIN BRANDS BASED ON } \\
\text { YOUR DISLIKE ON THE CONSUMER ANIMOSITY? }\end{array}$ & FREQ. & PERCENTAGE & CUM. \\
\hline STRONGLY DISAGREE & 2 & 6.67 & 6.67 \\
\hline DISAGREE & 3 & 10.00 & 16.67 \\
\hline NEUTRAL & 2 & 6.67 & 23.33 \\
\hline AGREE & 9 & 30.00 & 53.33 \\
\hline STRONGLY AGREE & 14 & 46.67 & 100.00 \\
\hline & & & \\
\hline
\end{tabular}

\subsubsection{Country of Origin}

H1: The country of origin limits the consumption of luxurious brands

H2: The country of origin does not limit the consumption of luxurious brands

Based on findings, most participants (50\%) strongly agree that the country of origin limits the consumption of luxurious brands.

Table 9. Origin Country

\begin{tabular}{|l|l|l|l|}
\hline $\begin{array}{l}\text { DO YOU } \\
\text { NEGLECT } \\
\text { CERTAIN } \\
\text { BRANDS BASED } \\
\text { ON YOUR DISLIKE } \\
\text { ON THE ORIGIN } \\
\text { COUNTRY? }\end{array}$ & FREQ & PERCENT & CUM \\
\hline $\begin{array}{l}\text { STRONGLY } \\
\text { DISAGREE }\end{array}$ & 3 & 10.00 & 10.00 \\
\hline DISAGREE & 2 & 6.67 & 16.67 \\
\hline NEUTRAL & 2 & 6.67 & 23.33 \\
\hline AGREE & 8 & 26.67 & 50.00 \\
\hline $\begin{array}{l}\text { STRONGLY } \\
\text { AGREE }\end{array}$ & 15 & 50.00 & 100.00 \\
\hline & 30 & 100.00 & \\
\hline
\end{tabular}

\subsubsection{Brand Feedback}

H1: Negative brand feedback limits consumption of luxurious goods

H2: Negative brand feedback does not limit the consumption of luxurious goods

Based on findings, most participants (46\%) strongly agree that brand feedback limits luxurious brands' consumption.

Table 10. Purchasing Decision

\begin{tabular}{|c|c|c|c|}
\hline $\begin{array}{l}\text { DOES A } \\
\text { NEGATIVE } \\
\text { CUSTOMER } \\
\text { FEEDBACK } \\
\text { LIMIT YOUR } \\
\text { NEXT } \\
\text { PURCHASI } \\
\text { NG } \\
\text { DECISION? }\end{array}$ & $\begin{array}{l}\text { FREQUEN } \\
\text { CY }\end{array}$ & $\begin{array}{l}\text { PERCENTA } \\
\text { GE }\end{array}$ & CUM. \\
\hline $\begin{array}{l}\text { STRONGLY } \\
\text { DISAGREE }\end{array}$ & 3 & 10.00 & 10.00 \\
\hline DISAGREE & 2 & 6.67 & 16.67 \\
\hline NEUTRAL & 2 & 6.67 & 23.33 \\
\hline AGREE & 9 & 30.00 & 53.33 \\
\hline DISAGREE & 14 & 46.67 & $\begin{array}{l}100.0 \\
0\end{array}$ \\
\hline & 30 & 100.00 & \\
\hline
\end{tabular}




\subsection{Results Analysis}

\subsubsection{Price of Luxury Goods}

Until recently, wealthy people were renowned for favoring designer labels with big logos to demonstrate their financial means. However, they are increasingly eschewing ostentation and overt shows of wealth [3]. Besides, the price of goods limits the belief of purchasing certain goods since people believe they are overpriced.

\subsubsection{Weakening Brand Value}

Partly, it may be attributable to consumers with a high cultural desire to differentiate themselves from the novel riches' extravagant conspicuous consumption and the idealistic consumption of lower social status consumers who erode a brand's image by consuming more large-scale variations of luxury goods, such as consumption of jewelry and consumption of expensive sneakers. Besides, partly, it may be attributable to an anonymous urban society where luxury purses, dresses, and automobiles are increasingly available for temporary rental or lease. Therefore, it is becoming increasingly difficult to determine whether a person driving a Ferrari owns it or rents it for a certain period.

\subsubsection{Inconspicuous consumption}

Consumers consider hiding their luxury logos since no one must know they own such costly consumer goods. The need for discreet luxury brands is reflected in the increasing demand for extraordinarily modest or no branding on luxury watches, briefcases, and apparel and an increased preference for experiential luxury over material luxury [4]. That means the upper class may choose to spend their money on a spa weekend or a trip to Hainan to play golf or a fine dining experience rather than on the newest designer product or sports vehicle model. While experiences may be noteworthy, they are much less so than carrying an LV purse emblazoned with the company's emblem. The movement toward experiencing luxury may be seen as a move toward inconspicuousness.

\subsubsection{Religion}

Religious consumers would steer clear of businesses that violate their religious principles and beliefs. Offensive advertising and marketing strategies that violate or offend consumers' religious views would result in a greater refusal rate [5]. Religious consumers would react if businesses violated their religious beliefs and values, and they would also regard any religious infringement as a grave threat to their religious personalities.

\subsubsection{Consumer Animosity}

Consumer animosity defines strong unfavorable sentiments against buying goods from a country or group that is despised. The majority of consumer hatred research has focused on the sentiments of citizens of one country against the goods. Consumer animosity has received considerable attention in the global marketing literature to predict global product buying behavior. Several studies investigate the connections between customer hostility and other factors such as consumer efficacy and consumers' readiness to engage in boycott action [6, 7]. Conflicts between nations are evident. Such conflicts may arise as a result of economic disagreements and regional conflicts.

\subsubsection{Country of Origin}

One of the most prominent research areas in global marketing is the country-of-origin cliché and its impact on customer behavior, which has received significant attention in recent years. Marketing researchers are interested in the impact of the nation of origin on customer perceptions and purchasing behavior. Consumers avoid buying goods from nations that have committed hostile military, economic or political actions against their own country since these crimes are painful and difficult to reconcile.

\subsubsection{Brand Feedback}

Brand response to negative e-WOM has also had harmful consequences. For example, negative management responses have resulted in a decrease in a purchase decision. One of the primary reasons customers utilize e-WOM messaging is to prevent making a poor purchase decision [8]. When it comes to negative brand feedback, giving it may serve as a dangerous signal for customers. This risk cue may result in decreased purchasing intentions. Considering that customers want to avoid unnecessary post-purchase interactions with customer care, the mere existence of brand feedback may dissuade buyers from purchasing an online product [8]. The problem is exacerbated by the fact that customers may sometimes believe that brand feedback is an effort by companies to promote themselves, akin to paid advertising.

\subsection{Suggestions}

Both consumer-focused advertisement and behavior modification strategies are required to promote more positive customer behavior. The first entails corporate marketing that demonstrates a "comprehensive knowledge of consumer requirements, purchasing behavior, and the factors affecting customers' purchase decisions" (Kalliny et al. 2018, 845). The second is social 
marketing that uses marketing methods to address social issues rather than economic objectives.

\section{CONCLUSION}

The price of the luxurious brands limits the consumers' belief not to purchase such goods. Wealthy individuals also shun away because of counterfeit products. Besides, wealthy individuals opt not to buy luxurious brands of their weakened brand value. The weakened brand value results from everyone possessing the good from specific place inclusion of low-class individuals. Furthermore, inconspicuous consumption of goods is a significant trend impacting the consumers' belief in consumption.

The thesis consists of several paragraphs that analyze whether belief system impact the consumer decisions towards purchasing luxurious and global brands. The results support the hypothesis that consumer behavior is increasingly affected by religion as a significant component of modern society. The study of religion's influence on organizational theory is becoming more critical due to the constant religious resurgence. Acknowledging the importance of religion and Halal considerations may enable modern businesses to avoid catastrophic marketing errors in domestic and international markets. Indicators that were previously utilized to signal conspicuousness (e.g., LV products) are currently being applied to fit in; subtle indicators are desired but might be even more so among the inconspicuous (Mortimer et al. 2015, 166). Besides, there is a shift away from luxury products toward adventures and experiences that are less recognizable by the public. It constantly changes the epicentre of consumer culture, offering an illuminating backdrop for showing that the essence of luxury is not necessarily associated with ostentatious consumption.

Consumers may have national animosity against a specific nation based on their views of how that country has mistreated and interacted with their own country. Research findings indicate the significance of the nation of origin on customer behavior (Roy et al. 2021, 495; Wu et al. 2017, 25). The research findings also propose that it should be the fifth ingredient of the marketing mix, after product, price, promotion, and distribution. At the moment, several disputes are occurring around the globe, and conflicts between countries may arise for various causes, including military confrontations, differences over foreign policy, economic problems, tensions in international commerce, and religious conflicts. Whenever customers perceive an indication regarding onerous post-purchase issues or contacts with customer service due to brand feedback, it may activate a mental schema that causes them to avoid purchasing or consuming the product.

Due to certain limitations, the findings of this study should be interpreted with caution. The small sample size constrains the study's breadth. Besides, the study was conducted online. Nevertheless, it is heartening to observe that consumers in this online study have distinct perceptions of status consumption. It highlights the need to conduct additional comparative research involving specific countries and cultures.

\section{ACKNOWLEDGMENT}

Thanks to professor, professor assistant and the other teachers in the helping of completing this essay. Professor has taught us the professional knowledge for us and stimulate me to have this topic of research. The assistant has helped us to narrow down our topic and the structure of my essay. Thanks to all the effort they have made. I was grateful for the invaluable insights and assistance from my professor that led the writing of this research paper. My sincere thanks also go to my fellow faculty members, who read my revisions and assisted me in making sense of the project confusion. Thanks to our university for awarding me a chance to learn and write research papers enabling me to expand my in-depth understanding of consumer behavior in sales and marketing. Finally, I am grateful to my parents and numerous friends who enabled me to complete the research in a suitable environment.

\section{REFERENCES}

[1] Ramya, N., \& Ali, M. Factors affecting consumer buying behavior, 2016: 2(10), 76-80. Retrieved 17 September 2021, from https://www.researchgate.net/profile/RamyaN/publication/316429866_Factors_affecting_consu mer_buying_behavior/links/58fd7b5e0f7e9ba3ba5 $5 \mathrm{f} 83 \mathrm{c} /$ Factors-affecting-consumer-buyingbehavior.pdf.

[2] Eckhardt, G., Belk, R., \& Wilson, J. The rise of inconspicuous consumption. Journal Of Marketing Management, 2015: $\quad$ 31(7-8), $\quad$ 807-826. https://doi.org/10.1080/0267257x.2014.989890

[3] Wu, Z., Luo, J., Schroeder, J., \& Borgerson, J. Forms of inconspicuous consumption. Marketing Theory, 2017: 17(4), 491-516. https://doi.org/10.1177/1470593117710983

[4] Dhaliwal, A. Determinants Affecting Consumer Behaviour With Regard To Counterfeit Products. International Journal Of Scientific Research And Management, 2016. https://doi.org/10.18535/ijsrm/v4i6.04

[5] Kalliny, M., Minton, E., \& Benmamoun, M. Affect as a driver to religious-based consumer boycotts: Evidence from qualitative and quantitative research in the United States. International Journal Of 
Consumer Studies, 2018: 42(6), 840-853. https://doi.org/10.1111/ijcs. 12450

[6] Lavorata, L. Influence of retailers' commitment to sustainable development on store image, consumer loyalty and consumer boycotts: Proposal for a model using the theory of planned behavior. Journal Of Retailing And Consumer Services, 2014: 21(6), 1021-1027.

https://doi.org/10.1016/j.jretconser.2014.01.003

[7] Bhandari, M., \& Rodgers, S. What does the brand say? Effects of brand feedback to negative eWOM on brand trust and purchase intentions. International Journal Of Advertising, 2017, 37(1), 125-141. https://doi.org/10.1080/02650487.2017.1349030

[8] Mortimer, G., Bougoure, U., \& Fazal-E-Hasan, S. Development and validation of the Self-Gifting Consumer Behaviour scale. Journal Of Consumer Behaviour, 2015: $\quad$ 14(3), $165-179$. https://doi.org/10.1002/cb.1506

[9] Roy, S., Singh, G., \& Shabnam, S. Modelling Customer Engagement Behaviour in Smart Retailing. Australasian Journal Of Information Systems, 2021:

25. https://doi.org/10.3127/ajis.v25i0.2967 